\title{
ГЛУБИНЫ ЗАЛЕГАНИЯ МАГНИТНЫХ ИСТОЧНИКОВ В АРКТИКЕ И ИХ СВЯЗЬ С ПАРАМЕТРАМИ ЛИТОСФЕРЫ
}

Середкина А. И., Филиппов С. В.

\begin{abstract}
Аннотация
В работе представлены результаты исследования глубин залегания магнитных источников в Арктике по данным глобальных моделей литосферного магнитного поля Земли EMAG2v3 и WDMAM 2.0. Анализ азимутально-усредненных Фурье-спектров мощности аномалий геомагнитного поля для 20 различных тектонических провинций показал, что глубина нижней границы магнитоактивного слоя литосферы изменяется от 25.3 до 38.1 км. При этом глубины центра масс и нижней границы литосферных магнитных источников определяются более устойчиво, чем глубина верхней границы. Полученные оценки глубин нижней границы были сопоставлены с длинноволновыми спутниковыми аномалиями литосферного геомагнитного поля, мощностью земной коры и литосферы, распределением температуры в верхней мантии. Показано, что глубина нижней границы литосферных магнитных источников не коррелирует со значениями модуля полного вектора литосферного магнитного поля на спутниковых высотах, находится в прямой зависимости от мощности литосферы и в обратной зависимости от средней температуры верхней мантии. Для большинства рассматриваемых структур магнитоактивный слой расположен в пределах земной коры, однако под глубоководными океаническими бассейнами и морем Лаптевых верхняя мантия обладает магнитными свойствами. Для моря Лаптевых полученные результаты свидетельствуют в пользу пассивного характера современных процессов растяжения на шельфе.
\end{abstract}

\section{Ключевые слова:}

магнитоактивный слой, литосферное геомагнитное поле, модель EMAG2v3, модель WDMAM 2.0, Фурье-спектр мощности аномалий геомагнитного поля, литосфера, Арктика 


\title{
ГЛУБИНЫ ЗАЛЕГАНИЯ МАГНИТНЫХ ИСТОЧНИКОВ В АРКТИКЕ И ИХ СВЯЗЬ С ПАРАМЕТРАМИ ЛИТОСФЕРЫ
}

\author{
А.И. Середкина, С.В. Филиппов \\ Институт земного магнетизма, ионосферы и распространения радиоволн \\ им. Н.В. Пушкова РАН, 108840, Россия, г. Москва, г. Троицк, Калужское шоссе, 4
}

\begin{abstract}
Аннотация
В работе представлены результаты исследования глубин залегания магнитных источников в Арктике по данным глобальных моделей литосферного магнитного поля Земли EMAG2v3 и WDMAM 2.0. Анализ азимутально-усредненных Фурье-спектров мощности аномалий геомагнитного поля для 20 различных тектонических провинций показал, что глубина нижней границы магнитоактивного слоя литосферы изменяется от 25.3 до 38.1 км. При этом глубины центра масс и нижней границы литосферных магнитных источников определяются более устойчиво, чем глубина верхней границы. Полученные оценки глубин нижней границы были сопоставлены с длинноволновыми спутниковыми аномалиями литосферного геомагнитного поля, мощностью земной коры и литосферы, распределением температуры в верхней мантии. Показано, что глубина нижней границы литосферных магнитных источников не коррелирует со значениями модуля полного вектора литосферного магнитного поля на спутниковых высотах, находится в прямой зависимости от мощности литосферы и в обратной зависимости от средней температуры верхней мантии. Для большинства рассматриваемых структур магнитоактивный слой расположен в пределах земной коры, однако под глубоководными океаническими бассейнами и морем Лаптевых верхняя мантия обладает магнитными свойствами. Для моря Лаптевых полученные результаты свидетельствуют в пользу пассивного характера современных процессов растяжения на шельфе.
\end{abstract}

Ключевые слова: магнитоактивный слой, литосферное геомагнитное поле, модель EMAG2v3, модель WDMAM 2.0, Фурье-спектр мощности аномалий геомагнитного поля, литосфера, Арктика 


\section{ВВЕДЕНИЕ}

Известно, что магнитное поле Земли может быть представлено в виде суммы трех компонент: главного (95\%), литосферного (4\%) и внешнего полей (1\%) [Яновский, 1978]. Литосферное, или аномальное геомагнитное поле, генерируется источниками, расположенными в земной коре и верхней мантии до глубин, где температура достигает температуры точки Кюри. С увеличением глубины температура растет, и ферромагнитные горные породы переходят в парамагнитное состояние.

Накопленный в последние десятилетия большой объем данных разновысотных геомагнитных съемок позволил построить достаточно детальные глобальные модели литосферного геомагнитного поля: EMAG2v2, EMAG2v3 и WDMAM 2.0 [Dyment et al., 2015; Lesur et al., 2016; Maus et al., 2009; Meyer et al., 2017]. В результате анализа этих и других региональных моделей с помощью различных методов инверсии [Bansal et al., 2011; Bouligand et al., 2009; Ravat et al., 2007; Spector, Grant, 1970; Tanaka et al., 1999 и др.] были определены глубины залегания литосферных магнитных источников для всей Земли в целом [Li et al., 2017; Tanaka, 2017] и ряда ее регионов [Цветков и др., 2018; Bansal et al., 2013; Hsieh et al., 2014; Li, Wang, 2016; Salazar et al., 2017; Salem et al., 2014; Tanaka, Ishikawa, 2005; Trifonova et al., 2009; Tsvetkov et al., 2018 и др.]. Проведенные исследования показали, что магнитоактивный слой (МАС) в среднем имеет большую мощность на континентах под древними платформами и щитами и утоняется под тектонически активными структурами. Была продемонстрирована зависимость между глубиной нижней границы МАС и возрастом океанического дна [Li et al., 2017]. В предположении одномерного кондуктивного теплопереноса и однородного вещественного состава было выведено корреляционное соотношение между глубиной нижней границей магнитных источников и тепловым потоком [Idarraga-Garcia, Vargas, 2018]. Для ряда регионов Южной Америки и Азии (Камчатка, Япония), характеризующихся высоким уровнем сейсмичности, были также установлены связи между МАС и мощностью сейсмоактивного слоя [Idarraga-Garcia, Vargas, 2018; Tanaka, Ishikawa, 2005; Tanaka, 2007]. Однако до сих пор остается дискуссионным вопрос о магнитных свойствах верхней мантии (см. обзор [Ferré et al., 2014]), и практически не рассматривались возможные связи между мощностями МАС и литосферы.

K настоящему времени для территории Арктики построены различные модели литосферного магнитного поля и проведен анализ выявленных аномалий [Верба, 2006; Глебовский и др., 2008; Gaina et al., 2011; Glebovsky et al., 2000; Døssing et al., 2013; Macnab et al., 1995; Verhoev et al., 1996]. Полученные результаты использованы для 
построения комплексных геофизических моделей строения земной коры и геодинамических реконструкций [Верба и др., 1989, 1998; Пискарев, 2016; Gaina et al., 2014; Petrov et al., 2016; Saltus et al., 2011]. Тем не менее, в связи со своим географическим положением $\left(>60^{\circ} \mathrm{N}\right)$ Арктика остается одним из наименее изученных регионов Земли, что подчеркивается в одном из последних обзоров геофизической изученности данной территории [Глебовский и др., 2018]. В частности, здесь практически не проводились детальные исследования по определению глубин залегания магнитных источников по имеющимся моделям литосферного магнитного поля, за исключением отдельных довольно ограниченных по площади областей на севере Канады [Gaudreau et al., 2019; Witter, Miller, 2017] и полярного Урала [Федорова и др., 2013, 2017]. Таким образом, наиболее полными источниками информации о параметрах МАС в Арктике остаются две глобальные модели [Li et al., 2017; Tanaka, 2017]. Причем имеющиеся оценки глубины залегания центра масс магнитных источников, полученные в работе [Tanaka, 2017], охватывают лишь южную часть Арктики $\left(<75^{\circ} \mathrm{N}\right)$, характеризуются довольно грубым разрешением ( 330 км) и не дают информации о распределении глубины нижней границы MAC. Данные о последней представлены в модели [Li et al., 2017], рассчитанной с учетом фрактального распределения намагниченности. Существенным недостатком фрактального подхода является задание единого для всей Земли параметра $\beta$, отражающего степень раздробленности среды. Как было показано в более ранних работах, обзор которых приведен в [Bouligand et al., 2009], значения $\beta$ могут меняться в широком диапазоне для регионов с различным геологическим строением. Таким образом, задание единого для всей Земли фрактального параметра, несомненно, приведет к неверному определению глубин для тех регионов, где модельное $\beta$ далеко от реального.

В связи с этим, в данной работе были поставлены следующие задачи:

- определить параметры МАС с помощью метода центроида [Tanaka et al., 1999], не требующего априорных знаний о строении среды, для 20 тектонических провинций Арктики (рис. 1);

- установить возможные взаимосвязи между параметрами МАС, аномалиями литосферного геомагнитного поля на спутниковых высотах, мощностью земной коры и литосферы, температурой в верхней мантии.

\section{ИСХОДНЫЕ ДАННЫЕ И МЕТОДЫ ИССЛЕДОВАНИЯ}

Чтобы повысить достоверность получаемых результатов, в качестве исходного материала для вычисления параметров МАС использовались две глобальные модели 
литосферного магнитного поля Земли: EMAG2v3 [Meyer et al., 2017] и WDMAM версии 2.0 [Dyment et al., 2015; Lesur et al., 2016]. В модели EMAG2v3 литосферное геомагнитное поле приведено к высоте 4 км над уровнем моря и имеет горизонтальное разрешение 2 угловые минуты (рис. 2a). В отличие от EMAG2v2 [Maus et al., 2009] и WDMAM 2.0, EMAG2v3 не содержит в себе априорной геологической информации, т.е. опирается только на непосредственные измерения геомагнитного поля, что является несомненным преимуществом этой модели. Модель WDMAM 2.0, основанная по сравнению с ее предшествующими вариантами [Khorhonen et al., 2007; Maus et al., 2009], на большем объеме исходных данных и вычисленная с применением усовершенствованных процедур их интерполяции, построена для высоты 5 км над уровнем моря с горизонтальным разрешением 3 угловые минуты (рис. 2б). Обе модели включают в себя данные морских, аэромагнитных, наземных и спутниковых геомагнитных съемок (данные спутника СНАМР). Следует отметить, что использование спутниковых данных для расчетов параметров МАС обеспечивает более надежное выделение нижней границы магнитных источников, что было экспериментально показано, например, в исследованиях на юге Китая [Wen et al., 2019].

Как указано выше, в настоящее время существует несколько различных подходов для оценки параметров МАС по азимутально-усредненным Фурье-спектрам мощности аномалий геомагнитного поля. Одни из них применяются для изучения изолированных намагниченных тел [Bhattacharyya, Leu, 1975a, b], другие - для описания их ансамблей с учетом случайного [Okubo et al., 1985; Ravat et al., 2007; Spector, Grant, 1970; Tanaka et al., 1999] или фрактального [Bansal et al., 2011; Bouligand et al., 2009; Li et al., 2017; Maus, Dimri, 1994; Maus et al., 1997] распределения намагниченности. В данной работе расчеты проводились в предположении случайного распределения намагниченности в МАС методом центроида [Okubo et al., 1985; Tanaka et al., 1999]. Выбор данного метода обусловлен тем, что он не требует никаких априорных сведений о строении среды, т.е. не требует задания закона изменения намагниченности с глубиной или значения фрактального параметра.

Если намагниченность в бесконечном в горизонтальных направлениях слое является случайной функцией координат, азимутально-усредненный Фурье-спектр мощности аномалий геомагнитного поля $\left(\Phi_{\Delta T}\right)$ согласно [Blakely, 1995] имеет следующий вид:

$$
\Phi_{\Delta T}(|k|)=A e^{-2|k| Z_{t}}\left(1-e^{-|k|\left|Z_{b}-Z_{t}\right|}\right)^{2}
$$


где $A$ - const; $|k|=\sqrt{k_{x}^{2}+k_{y}^{2}}$ - модуль волнового числа, $Z_{\mathrm{t}}$ и $Z_{\mathrm{b}}$ - глубины верхней и нижней границы МАС соответственно.

Для длин волн хотя бы в два раза меньших, чем мощность коры, глубина верхней границы МАС определяется из (1) следующим образом [Okubo et al., 1985; Tanaka et al., 1999]:

$$
\ln \left[\Phi_{\Delta T}(|k|)^{\frac{1}{2}}\right]=\ln B-|k| Z_{t}
$$

где $B$ - const.

Для больших длин волн глубина центра масс MAC $\left(Z_{0}\right)$ связана со спектром как

$$
\ln \left[\Phi_{\Delta T}(|k|)^{\frac{1}{2}} /|k|\right]=\ln C-|k| Z_{0}
$$

где $C$ - const.

Глубина нижней границы МАС выражается через найденные параметры как [Tanaka et al., 1999]:

$$
Z_{b}=2 Z_{0}-Z_{t}
$$

Таким образом, согласно соотношениям (2)-(4), полученным для случайного распределения намагниченности в слое, глубины залегания литосферных магнитных источников могут быть полностью определены по наклону спектра литосферного поля для различных частотных диапазонов. В случае, если распределение намагниченности будет отличаться от указанной выше модели, очевидно, будет требоваться другой математический аппарат для решения поставленной задачи. В частности, при увеличении намагниченности с глубиной соотношения (2)-(4) завышают оценки глубин нижней границы МАС, а если распределение намагниченности в слое является фрактальным занижают эти оценки [Bansal et al., 2011].

Известно, что оптимальный размер окна, в котором вычисляется спектр, должен в 4-6 раз превышать исследуемые глубины [Blakely, 1995; Okubo et al., 1985]. Согласно современным представлениям верхняя мантия древних щитов и платформ может обладать ненулевой намагниченностью [Ferré et al., 2014]. При этом максимальная мощность земной коры для исследуемых структур достигает около 55 км под Балтийским щитом [Laske et al., 2013; Seredkina, 2019]. Принимая это во внимание, в данной работе для анализа использовалось окно размером 300 х 300 км. Как показывают синтетические тесты [Ravat et al., 2007], такой размер окна позволяет получать надежные средние оценки искомых параметров, но не позволяет проследить локальные вариации глубин, что, однако, и не входило в задачи исследования. 
В данной работе глубина $Z_{0}$ определялась в диапазоне волновых чисел от максимума спектра до $0.022 \mathrm{kM}^{-1}$, а $Z_{\mathrm{t}}$ - приблизительно от 0.050 до $0.100 \mathrm{kм}^{-1}$ аналогично тому, как это предложено в [Tanaka, 2007, 2017; Tanaka et al., 1999]. Вычисление азимутально-усредненных Фурье-спектров мощности аномалий геомагнитного поля проводилось с помощью пакета Fourpot 1.3b [Pirttijärvi, 2015]. Линейные зависимости, аппроксимирующие наблюденный спектр, рассчитывались методом наименьших квадратов. Примеры определения глубин залегания магнитных источников для моря Лаптевых и складчатых поясов Аляски показаны на рис. 3.

Погрешности вычисления параметров МАС рассчитывались по формуле, предложенной в публикациях [Okubo, Matsunaga, 1994; Salazar et al., 2017]:

$$
\varepsilon=\frac{\sigma}{\left|k_{2}\right|-\left|k_{1}\right|}
$$

где $\sigma$ - среднеквадратичное отклонение линейной аппроксимации от наблюденного спектра; $\left|k_{2}\right|$ и $\left|k_{1}\right|$ - верхняя и нижняя граница диапазона волновых чисел, в котором определялись искомые параметры (рис. 3).

Отметим, что формула (5) не учитывает погрешности исходных данных, которые могут быть весьма существенными, особенно в приполярных областях. Так для большей части Арктики согласно модели EMAG2v3 максимальная величина ошибок составляет 167 нТл [Meyer et al., 2017]. Из рассматриваемых нами тектонических провинций исключением является территория Аляски, для которой ошибки намного ниже (36 нТл). Чтобы оценить степень влияния погрешностей исходных данных на результаты вычисления глубин залегания магнитных источников при помощи метода центроида нами был проведен следующий численный эксперимент. Для двух регионов с максимальной и минимальной величинами ошибок - моря Ляптевых и складчатых поясов Аляски (рис. 1, табл. 2) - к значениям аномального геомагнитного поля, заданным моделью EMAG2v3, был добавлен равномерно распределенный случайный шум с амплитудой \pm 167 и \pm 36 нТл соответственно (см. врезки на рис. За), а затем рассчитаны спектры и искомые параметры MAC.

Результаты эксперимента показали, что добавление шума к исходным данным наиболее сильно сказывается на коротковолновой части спектра, в которой определяется глубина верхней границы литосферных магнитных источников (рис. Зв). При этом наблюдается выполаживание спектра, пропорциональное максимальной амплитуде шума, и, как следствие, уменьшение значения глубины верхней границы MAC $\left(\mathrm{Z}_{\mathrm{t}}\right)$. Как видно из рассмотренных примеров, разница в оценках $Z_{t}$ может достигать $~ 1.5$ км, т.е. для отдельных регионов может достигать $80 \%$ от определяемой глубины верхней границы 
(рис. Зв, табл. 2). Однако длинноволновая часть спектра, по которой определяется глубина центра масс магнитных источников, даже при добавлении шума с амплитудой \pm 167 нТл остается практически неизменной (рис. 3б). Благодаря этому вариации в оценках глубин $\mathrm{Z}_{0}$ не превышают сотен метров, т.е. на два порядка меньше характерных значений глубин (не превышают $1 \%$ от определяемых величин). Учитывая, что в соотношении (4) $\mathrm{Z}_{0}>>\mathrm{Z}_{\mathrm{t}}$ (рис. 3, табл. 2), влияние ошибок исходных данных на определение глубины нижней границы MAC $\left(Z_{b}\right)$ будет невелико. Так, с учетом шума для моря Лаптевых $Z_{b}$ составит 40.3 км, а для складчатых поясов Аляски - 31.1 км (см. рис. 3). Т.е. отклонения в $Z_{b}$ не превышают 2 км (менее 3\% от определяемых величин), что примерно сопоставимо с разницей в оценках глубин нижней границы, полученных для моделей EMAG2v3 и WDMAM 2.0 (см. табл. 2).

\section{МОДЕЛИ, ИСПОЛЬЗУЕМЫЕ ДЛЯ АНАЛИЗА РЕЗУЛЬТАТОВ}

Для выявления возможных зависимостей между глубинами залегания магнитных источников и другими известными параметрами литосферы, результаты проведенных расчетов были сопоставлены с длинноволновыми аномалиями литосферного геомагнитного поля, мощностью земной коры и литосферы и распределением температуры в верхней мантии. Значения модуля полного вектора литосферного геомагнитного поля на высоте 350 км задавались согласно глобальной модели MF6 (рис. 2в), построенной по данным спутника CHAMP [Maus et al., 2008]. Данная модель представляет литосферное геомагнитное поле сферическими гармониками до 120 степени, что соответствует пространственному разрешению на поверхности Земли равному 333 км. Из сопоставления рис. 1 и рис. 2в видно, что значения модуля полного вектора литосферного геомагнитного поля на спутниковых высотах явным образом не связаны с геологическим строением рассматриваемого региона. Например, положительные аномалии интенсивностью до 25 нТл наблюдаются как под древними стабильными щитами (Балтийским и Гренландским), так и под складчатыми поясами Аляски и глубоководной океанической котловиной Макарова. В то же время такие разнородные структуры как юго-восточная часть Балтийского щита, Западно-Сибирская платформа, Верхоянский складчатый пояс, Евразийский, Канадский и Гренладско-Норвежский бассейны характеризуются отрицательными значениями аномалий литосферного геомагнитного поля.

Для исследования зависимости между глубиной нижней границы МАС и средней температурой мантийной части литосферы для океанических бассейнов и окраинных морей использовались средние значения температуры в верхней мантии на глубинах от 80 
до 150 км, рассчитанные с помощью инверсии скоростей S-волн с учетом различного вещественного состава под разновозрастными структурами [Lebedev et al., 2017]. В пределах континентальной части Арктики для анализа была выбрана температурная модель TC1 [Artemieva, 2006], основанная на измерениях теплового потока, результатах исследований мантийных ксенолитов и данных геоэлектрики. В этом случае для приведения обеих моделей к одному диапазону глубин средняя температура на глубине 80-150 км оценивалась нами следующим образом. Сначала по распределениям температуры на глубинах 50 и 150 км рассчитывался температурный градиент, затем вычислялась температура на глубине 80 км и среднее значение в рассматриваемом диапазоне. Из табл. 1 видно, что обе модели демонстрируют схожие тенденции в распределении температуры под различными тектоническими структурами. Так, древние щиты и платформы характеризуются наиболее холодной верхней мантией, в то время как литосфера под складчатыми поясами прогрета до температур более $1000{ }^{\circ} \mathrm{C}$. Однако разница в абсолютных значениях температуры между рассматриваемыми моделями может достигать сотен ${ }^{\circ} \mathrm{C}$, что, наиболее вероятно, обусловлено различиями в исходных данных и методах расчета, а также отличиями моделируемого вещественного состава от реального.

Мощность земной коры и литосферы оценивалась по 3D распределению скоростей S-волн в коре и верхней мантии, рассчитанному методом поверхностно-волновой томографии по данным дисперсии групповых скоростей волн Рэлея [Середкина, 2019; Seredkina, 2019]. Выбранная модель характеризуется горизонтальным разрешением 400 км для центральной части Арктики (> 70 $\mathrm{N})$, северо-востока Евразии и Аляски. Для остальной части исследуемой области оно превышает 600 км. Однако как было показано в [Seredkina, 2019], даже при таком разрешении полученное распределение скоростей позволяет проследить основные особенности глубинного строения, выявленные в более детальных исследованиях отдельных регионов Арктики [Pedersen et al., 2013; Rickers et al., 2013]. Также следует отметить, что в рассматриваемой модели в качестве априорной информации учитывались результаты многочисленных работ по изучению земной коры, что делает ее использование в дальнейших рассуждениях более предпочтительным по сравнению, например, с глобальной моделью CRUST 1.0 [Laske et al., 2013]. Так, в последней упомянутой модели мощность земной коры под Баренцевым морем составляет 30-35 км (рис. 4б), в то время как по данным сейсмопрофилирования [Bungum et al., 2005] она увеличивается с запада на восток от 20 до 38 км, что с учетом горизонтального разрешения отражено в [Seredkina, 2019] (рис. 4а). 


\section{РЕЗУЛЬТАТЫ ИССЛЕДОВАНИЯ И ИХ ОБСУЖДЕНИЕ}

Результаты проведенных расчетов глубин центра масс $\left(Z_{0}\right)$, верхней $\left(Z_{t}\right)$ и нижней границ $\left(Z_{\mathrm{b}}\right)$ литосферных магнитных источников с погрешностями вычислений $\left(\varepsilon_{\mathrm{t}}, \varepsilon_{0}\right)$ для моделей EMAG2v3 и WDMAM 2.0 для 20 различных тектонических провинций Арктики приведены в табл. 2. Для модели WDMAM 2.0 средняя погрешность определения глубины верхней границы магнитных источников составляет 6\%, а для глубины центра масс она несколько выше - 9\%. Для модели EMAG2v3 значения погрешностей для обоих параметров примерно одинаковы ( 9\%). Максимальная разница в значениях глубин центра масс, вычисленных с использованием различных исходных данных, не превышает 1.2 км, что сопоставимо с погрешностью определений $Z_{0}$. При этом глубины верхней границы MAC сильнее зависят от выбора модели. Так, максимальные отклонения оценок $Z_{t}$, полученных по различным данным, могут достигать 1.1 км, что составляет около 40\% от среднего значения определяемого параметра. Возможной причиной таких существенных расхождений оценок $Z_{\mathrm{t}}$ является отличие в высотах и горизонтальном разрешении используемых моделей литосферного магнитного поля, которые наиболее сильно влияют на коротковолновую часть спектра магнитных аномалий. Как показал численный эксперимент с добавлением случайного шума к данным модели EMAG2v3, сам спектр данной части аномального магнитного поля с ростом шума ведёт себя довольно неустойчиво (рис. 3), что также может быть причиной расхождения оценок $Z_{t}$, полученных по разным моделям. Что касается глубины нижней границы магнитных источников $\left(Z_{\mathrm{b}}\right)$, то разница в ее оценках по моделям EMAG2v3 и WDMAM 2.0 не превышает 7\% от определяемой величины. Для последующего сопоставления с параметрами литосферы и анализа полученных результатов будут использованы средние по обеим исходным

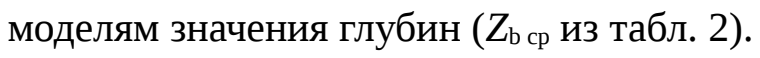

Глубина нижней границы МАС изменяется от 25.3 км под Колымским складчатым поясом до 38.1 км под северной Гренландией (табл. 2). Для окраинных морей, существенно различающихся по своему глубинному строению, степени тектонической и сейсмической активности, положение этой границы варьируется в довольно широком диапазоне 31-37 км. В то же время под всеми рассматриваемыми глубоководными океаническими бассейнами разного возраста с учетом погрешностей вычислений глубина нижней границы литосферных магнитных источников примерно одинакова и составляет 27 км. Следует отметить, что выявленные закономерности в вариациях глубины $Z_{\mathrm{b}}$ под различными тектоническими структурами хорошо согласуются с глобальной моделью [Li et al., 2017], однако абсолютные значения глубин несколько различаются за счет 
использования различных методов инверсии (с учетом случайного или фрактального распределения намагниченности в МАC), упомянутых выше. Также отметим, что для Канадского щита оценка $Z_{\mathrm{b}}(32 \pm 3$ км), полученная с применением фрактального метода, учетом априорной информации о мощности осадочного слоя и варьируемым параметром $\beta$ [Gaudreau et al., 2019], практически совпадает с результатом данной работы (32.3 км).

Зависимости между глубиной нижней границы магнитных источников и рассматриваемыми параметрами литосферы показаны на рис. 5. Из рис. 5а видно, что глубина нижней границы МАС не зависит от значений модуля полного вектора литосферного магнитного поля на высоте 350 км. Скорее всего, наблюденные длинноволновые аномалии геомагнитного поля связаны не только с вариациями мощности MAC, но и изменением его вещественного состава [Trifonova et al., 2009]. Это подтверждает и рис. 5б, где в предположении 1D кондуктивного теплопереноса и одинакового вещественного состава должна наблюдаться линейная обратно пропорциональная зависимость между глубиной нижней границы магнитных источников и средней температурой литосферы. Однако на рис. $5 б$ на фоне общего линейного тренда наблюдается довольно сильный разброс точек, вероятно, обусловленный тем, что температура точки Кюри существенно зависит от состава магнитных минералов. Так, для чистого магнетита она составляет $580^{\circ} \mathrm{C}$ [Hurt et al., 1995] и может уменьшаться до 150$200^{\circ}$ С при увеличении содержания титана в титаномагнетите [Stacey, Banerjee, 1974; Nozharov, Veljovich, 1983] и увеличиваться до $620^{\circ}-1100^{\circ}$ С в ультраосновных породах, подвергшихся частичной серпентинизации [Haggerty, 1978]. Кроме того, как показывают последние экспериментальные исследования [McEnroe et al., 2004, 2018], даже при одном вещественном составе температура точки Кюри может изменяться в зависимости от давления. Однако этот вопрос пока изучен довольно слабо. Сильное отклонение от линейного тренда на рис. $5 б$ для точки, соответствующей морю Лаптевых, вероятнее всего, обусловлено тем, что температура в модели [Lebedev et al., 2017] сильно преувеличена за счет заниженных значений скоростей S-волн, что видно в последующих сейсмотомографических реконструкциях рассматриваемого региона [Seredkina, 2019].

На наш взгляд, наиболее явно выраженная прямо пропорциональная зависимость прослеживается между глубиной нижней границы магнитных источников и мощностью литосферы (рис. 5в). Схожие результаты были получены в Карибском регионе [Salazar et al., 2017] с использованием различных подходов к оценке мощности МАС. Кроме того, те же тенденции были выявлены нами ранее для меридионального профиля, начинающегося 
на Сибирской платформе $\left(60^{\circ} \mathrm{N}, 113^{\circ} \mathrm{E}\right)$ и заканчивающегося в Забайкалье $\left(50^{\circ} \mathrm{N}, 113^{\circ} \mathrm{E}\right)$ [Середкина, Филиппов, 2019].

Как видно из рис. 5г, глубина нижней границы MAC не зависит от мощности земной коры. Следует отметить, что в настоящее время вопрос о возможной намагниченности верхней части мантии является дискуссионным. Первые исследования магнитных свойств мантийных ксенолитов позволили сделать предположение, что граница Мохо может приближенно рассматриваться в качестве нижней границы MAC [Wasilewski et al., 1979; Wasilewski, Mayhew, 1992], что в пределах точности расчетов согласуется с геомагнитными данными, полученными в различных регионах Земли [Bansal et al., 2011, 2013; Salem et al., 2014; Trifonova et al., 2009]. Однако результаты последующих аналогичных работ, основанные на большем количестве изучаемых образцов, показали, что магнетит входит в состав пород верхней мантии, и, соответственно, последняя может обладать магнитными свойствами [Ferré et al., 2013; Friedman et al., 2014]. При этом к регионам, в которых наиболее вероятно МАС превосходит мощность земной коры, относятся архейские и протерозойские щиты, зоны субдукции и океанические бассейны [Ferré et al., 2014]. Такое предположение подтверждается во многих работах, использующих различные подходы к определению мощности MAC [Abound et al., 2016; Arnaiz-Rodríguez, Orihuela, 2013; Idarraga-Garcia, Vargas, 2018; Li, Wang, 2016]. Из рис. 5г следует, что под глубоководными океаническими бассейнами и морем Лаптевых верхняя мантия характеризуется ненулевой намагниченностью, причем во всех случаях разница между исследуемыми параметрами превышает погрешности их определения.

В случае с морем Лаптевых независимым подтверждением возможной намагниченности верхней части мантии являются последние данные о глубинах очагов землетрясений средних магнитуд, достигающих 38 км [Seredkina, Melnikova, 2018], и результаты более ранних детальных исследований микросейсмичности с помощью временных локальных сетей сейсмических станций [Аветисов, 1991; Ковачев и др., 1994]. С геодинамической точки зрения такая большая глубина залегания нижней границы магнитных источников (табл. 2) в совокупности с достаточно мощной литосферой (рис. 5в) [Seredkina, 2019] и очагами землетрясений в верхней мантии, свидетельствует в пользу того, что современное растяжение коры на шельфе моря Лаптевых [Имаева и др., 2017; Seredkina, Melnikova, 2018] не может быть объяснено в рамках гипотез «активного» рифтинга, связанного как с продолжением хребта Гаккеля [Виноградов, 1984; Ким, 1986], так и с существованием здесь мантийного плюма [Grachev, 2003]. Вероятнее всего, оно обусловлено либо относительными движениями на границе Северо-Американской и 
Евразийской литосферных плит [Drachev, Shkarubo, 2017; Mazur et al., 2015], либо движениями Лаптевоморской микроплиты, выделяемой по сейсмологическим данным [Avetisov, 1999].

\section{ВЫВОДЫ}

В работе выполнен спектральный анализ литосферного геомагнитного поля, заданного глобальными моделями EMAG2v3 и WDMAM 2.0, и на его основе получены оценки глубин центра масс, верхней и нижней границ МАС для 20 различных тектонических провинций Арктики. Полученные результаты, сопоставленные с длинноволновыми спутниковыми аномалиями литосферного геомагнитного поля, мощностью земной коры и литосферы, распределением температуры в верхней мантии, позволяют сделать для исследуемого региона следующие выводы.

1. Глубины центра масс и нижней границы МАС, при их определении методом центроида, по данным моделей EMAG2v3 и WDMAM 2.0 определяются устойчиво, в отличие от глубины верхней границы.

2. Изменения модуля полного вектора литосферного геомагнитного поля на спутниковых высотах (спутниковые аномалии литосферного геомагнитного поля) над рассматриваемыми структурами явным образом не коррелируют с изменениями глубины нижней границы МАС под ними. Одним из объяснений такой картины могут быть вариации вещественного состава горных пород.

3. Глубина нижней границы МАС находится в прямой зависимости от мощности литосферы и в обратной зависимости от средней температуры верхней мантии.

4. Глубина нижней границы МАС не зависит от мощности земной коры.

5. Верхняя мантия под глубоководными океаническими бассейнами и морем Лаптевых обладает магнитными свойствами.

6. Для моря Лаптевых полученные результаты свидетельствуют в пользу пассивного характера современных процессов растяжения на шельфе.

Авторы выражают благодарность канд. геол.-мин. наук К.В. Новикову (ФГБУ «Гидроспецгеология», г. Москва) за консультации по тематике данной работы. Также авторы благодарят рецензентов за конструктивные замечания.

\section{ЛИТЕРАТУРА}

Аветисов Г.П. Гипоцентрия и фокальные механизмы землетрясений дельты р. Лены и ее обрамления // Вулканология и сейсмология, 1991, № 6, с. 59-69. 
Верба В.В. Природа аномального магнитного поля провинции ЦентральноАрктических поднятий в Амеразийском бассейне Северного Ледовитого океана // Геофизический журнал, 2006, т. 28, № 5, с. 95-103.

Верба В.В., Волк В.Э., Губернов А.П. Комплексная геофизическая модель земной коры Арктического бассейна // Теория и практика региональных геофизических исследований Мирового Океана и Антарктики. Л., изд-во ПГО «Севморгеология», 1989, с. $25-31$.

Верба В.В., Ким Б.И., Волк В.Э. Строение земной коры арктического региона по геофизическим данным / Геолого-геофизические характеристики литосферы Арктического региона. Вып. 2. Аветисов Г.П., Погребицкий Ю.Е. (Ред.)/ СПб., изд-во ВНИИОкеангеология, 1998, с. 12-28.

Виноградов В.А. Море Лаптевых / В кн. Геологическое строение СССР и закономерности размещения полезных ископаемых. Грамберг И.С., Погребицкий Ю.Е. (Ред.)/ Л., изд-во Недра, 1984, т. 9, Моря Советской Арктики, с. 50-60.

Глебовский В.Ю., Верба В.В., Каминский В.Д. Потенциальные поля Арктического бассейна: история изучения, аналоговые и современные цифровые обобщения / 60 лет в Арктике, Антарктике и Мировом Океане. Иванов В.Л., Каминский В.Д. (Ред.)/ СПб., изд-во ВНИИОкеангеология, 2008. с. 93-109.

Глебовский В.Ю., Черных А.А., Каминский В.Д., Васильев В.В., Корнева М.С., Суханова А.В., Редько А.Г., Яковенко И.В. Основные итоги и планы дальнейших магнитометрических и гравиметрических исследований в Северном Ледовитом океане / 70 лет в Арктике, Антарктике и Мировом океане. Сборник научных трудов. Каминский В.Д., Аветисов Г.П., Иванов В.Л. (Ред.)/ СПб., изд-во ВНИИОкеангеология, 2018, с. 196-208.

Имаева Л.П., Имаев В.С., Козьмин Б.М., Мельникова В.И., Середкина А.И., Маккей К.Д., Ашурков С.В., Смекалин О.П., Овсюченко А.Н., Чипизубов А.В., Сясько А.А. Сейсмотектоника северо-восточного сектора Российской Арктики. Новосибирск, изд-во СО РАН, 2017, 136 с.

Ким Б.И. Структурное продолжение рифтовой долины хребта Гаккеля на Лаптевском шельфе. // Структура и история развития Северного Ледовитого океана. Л., изд-во ПГО «Севморгеология», 1986, с. 133-139.

Ковачев С.А., Кузин И.П., Соловьев С.Л. Кратковременное изучение микросейсмичности губы Буор-Хая, море Лаптевых, с помощью донных сейсмографов // Физика Земли, 1994, № 7-8, с. 65-76. 
Пискарев А.Л. Арктический бассейн (геология и морфология). СПб., изд-во ВНИИОкеангеология, 2016, 291 с.

Середкина А.И. Поверхностно-волновая томография Арктики // Физика Земли, 2019, № 3, c. 439 - 450. doi:10.1134/S106935131903008X.

Середкина А.И., Филиппов С.В. Параметры магнитоактивного слоя литосферы для профиля Сибирская платформа - Забайкалье по данным модели WDMAM 2.0 // Геомагнетизм и аэрономия, 2019, т. 59, № 6, с. 810-818. doi:10.1134/S0016794019060099.

Федорова Н.В., Колмогорова В.В., Рублев А.Л., Цидаев А.Г. Магнитная модель северо-восточной части Европы // Геофизические исследования, 2013, т. 14, № 2, с. 25-37.

Федорова Н.В., Рублев А.Л., Муравьев Л.А., Колмогорова В.В. Магнитные аномалии и модель распределения намагниченности в земной коре приполярного и полярного секторов Уральского региона // Геофизический журнал, 2017, т. 39, № 1, с. 111122.

Цветков Ю.П., Новиков К.В., Иванов А.А., Филиппов С.В., Брехов О.М., Бондарь Т.Н. Глубины залегания источников аномального магнитного поля по наземным и аэростатным магнитным данным // Современные проблемы дистанционного зондирования Земли из космоса, 2018, т. 15, № 3, с. 80-87.

Яновский Б.М. Земной магнетизм. Л., изд-во ЛГУ, 1978, 592 с.

Aboud E., Alotaibi A.M., Saud R. Relationship between Curie isotherm surface and Moho discontinuity in the Arabian shield, Saudi Arabia // J. Asian Earth Sci., 2016, v. 128. p. 4253. http://dx.doi.org/10.1016/j.jseaes.2016.07.025.

Amante C., Eakins B.W. ETOPO1. 1 Arc-minute global relief model: Procedures, data sources and analysis, NOAA Technical Memorandum NESDIS NGDC-24. 2009. National Geophysical Data Center, NOAA. doi:10.7289/V5C8276M.

Arnaiz-Rodríguez M.S., Orihuela N. Curie point depth in Venezuela and the Eastern Caribbean // Tectonophysics, 2013, v. $\quad$ 590, $\quad$ p. $\quad 38-51$. http://dx.doi.org/10.1016/j.tecto.2013.01.004.

Artemieva I.M. Global $1^{\circ} \times 1^{\circ}$ thermal model TC1 for the continental lithosphere: Implications for lithosphere secular evolution // Tectonophysics, 2006, v. 416, p. 245-277. doi:10.1016/j.tecto.2005.11.022.

Avetisov G.P. Geodynamics of the zone of continental continuation of Mid-Arctic earthquakes belt (Laptev Sea) // Phys. Earth Planet. Inter., 1999, v. 114, p. 59-70.

Bansal A.R., Gabriel G., Dimri V.P., Krawczyk C.M. Estimation of depth to the bottom of magnetic sources by a modified centroid method for fractal distribution of sources: an 
application to aeromagnetic data in Germany // Geophysics, 2011, v. 76, N 3, L11-L22. doi:10.1190/1.3560017.

Bansal A.R., Anand S.P., Rajaram M., Rao V.K., Dimri V.P. Depth to the bottom of magnetic sources (DBMS) from aeromagnetic data of Central India using modified centroid method for fractal distribution of sources // Tectonophysics, 2013, v. 603, p. 155-161. http://dx.doi.org/10.1016/j.tecto.2013.05.024.

Bhattacharyya B.K., Leu L.-K. Spectral analysis of gravity and magnetic anomalies due to two-dimensional structures // Geophysics, 1975a, v. 40, N 6, p. 993-1013.

Bhattacharyya B.K., Leu L.-K. Analysis of magnetic anomalies over Yellowstone national park: mapping of Curie point isothermal surface for geothermal reconnaissance // J. Geophys. Res., 1975b, v. 80, N 32, p. 4461-4465.

Blakely R.J. Potential theory in gravity and magnetic applications. Cambridge, U.K., Cambridge University Press, 1995, 441 p.

Bouligand C., Glen J.M.G., Blakely J. Mapping Curie temperature depth in the western United States with a fractal model for crustal magnetization // J. Geophys. Res., 2009, v. 114, B11104. doi:10.1029/2009JB006494.

Bungum H., Ritzmann O., Maercklin N., Faleide J.I., Mooney W.D., Detweiler S.T. Three-dimensional model for the crust and upper mantle in the Barents Sea Region // EOS, Trans. Am. Geophys. Un., 2005, v. 86, p. 160-161.

Døssing A., Jackson H.R., Matzka J., Einarsson I., Rasmussen T.M., Olesen A.V., Brozena J.M. On the origin of the Amerasia Basin and the High Arctic large igneous province Results of new aeromagnetic data // Earth Planet. Sci. Lett., 2013, v. 363, p. 219-230. http://dx.doi.org/10.1016/j.epsl.2012.12.013.

Drachev S.S., Shkarubo S.I. Tectonics of the Laptev Shelf, Siberian Arctic / In: CircumArctic Lithosphere evolution. Pease V, Coakley B. (ed) Geological Society, London, Special Publications, 2017, p. 460. https://doi.org/10.1144/SP460.15.

Dyment J., Lesur V., Hamoudi M., Choi Y. , Thebault E., Catalan M. World Digital Magnetic Anomaly Map version 2.0. 2015. http://www.wdmam.org/.

Ferré E.C., Friedman S.A., Martín-Hernández F., Feinberg J.M., Conder J.A., Ionov D.A. The magnetism of mantle xenoliths and potential implications for sub-Moho magnetic sources // Geophys. Res. Lett., 2013, v. 40, p. 105-110. http://dx.doi.org/10.1029/2012GL054100. 
Ferré E.C., Friedman S.A., Martín-Hernández F., Feinberg J.M., Till J.L., Ionov D.A., Conder J.A. Eight good reasons why the uppermost mantle could be magnetic // Tectonophysics, 2014, v. 624-625, p. 3-14. http://dx.doi.org/10.1016/j.tecto.2014.01.004.

Friedman S.A., Feinberg J.M., Ferré E.C., Demory F., Martín-Hernández F., Conder J.A., Rochette P. Craton vs. rift uppermost mantle contributions to magnetic anomalies in the United States interior // Tectonophysics, 2014, v. 624-625, p. 15-23. http://dx.doi.org/10.1016/j.tecto.2014.04.023.

Gaina C., Medvedev S., Torsvik T.H., Koulakov I., Werner S.C. 4D Arctic: a glimpse into the structure and evolution of the Arctic in the light of new geophysical maps, plate tectonics and tomographic models // Surv. Geophys., 2014, v. 35, p. 1095-112. doi:10.1007/s10712-0139254-y.

Gaina C., Werner S., Saltus R., Maus S. Circum-Arctic mapping project: new magnetic and gravity anomaly maps of the Arctic // Geol. Soc. Lond. Mem., 2011, v. 35, N 1, p. 39-48.

Gaudreau É., Audet P., Schneider D.A. Mapping Curie depth across western Canada from a wavelet analysis of magnetic anomaly data // J. Geophys. Res.: Solid Earth, 2019, v. 124, p. 4365-4385. https://doi.org/10.1029/2018JB016726.

Glebovsky V., Kovacs L., Maschenkov S., Brozena J. Joint compilation of Russian and US Navy aeromagnetic data in the central Arctic seas // Polarforschung, 2000, v. 68, p. 35-40.

Grachev A.F. The Arctic rift system and the boundary between the Eurasian and North American lithospheric plates: new insight to plate tectonic theory // Russ. J. Earth Sci., 2003, v. 5 N 5, p. 307-345. doi:10.2205/2003ES000135.

Haggerty S.E. Mineralogical constraints on Curie isotherms in deep crustal magnetic anomalies // Geophys. Res. Lett., 1978, v. 5, p. 105-108.

Hsieh H.-H., Chen C.-H., Lin P.-Y., Yen H.-Y. Curie point depth from spectral analysis of magnetic data in Taiwan // J. Asian Earth Sci., 2014, v. 90, p. 26-33. http://dx.doi.org/10.1016/j.jseaes.2014.04.007.

Hurt C.P., Moskowitz B.M., Banerjee S.K. Magnetic properties of rocks and minerals / Rock physics and phase relations. A handbook of physical constants / AGU Reference Shelf Series, v. 3, Washington DC, USA, AGU, 1995, p. 189-204.

Idarraga-Garcia J., Vargas C.A. Depth to the bottom of magnetic layer in South America and its relationship to Curie isotherm, Moho depth and seismicity behavior // Geodesy and Geodynamics, 2018, v. 9, p. 93-107. https://doi.org/10.1016/j.geog.2017.09.006. 
Khorhonen J.K., Fairhead J.D., Hamoudi M. et al. Magnetic anomaly map of the world - carte des anomalies magnétiques du monde. 1st Edition. Paris, France: Commission for Geological Map of the World, 2007.

Laske G., Masters G., Ma Z., Pasyanos M. Update on CRUST1.0 - A 1-degree global model of Earth's crust / European Geoscience Union General Assembly. Vienna, Austria, 7-12 April, 2013. 2013. N EGU2013-2658.

Lebedev S., Schaeffer A.J., Fullea J., Pease V. Seismic tomography of the Arctic region: inferences for the thermal structure and evolution of the lithosphere/ Circum-Arctic lithosphere evolution / London, UK, Geological Society, Special Publications, 2017, v. 460, p. 419-440.

Lesur V., Hamoudi M., Choi Y., Dyment J., Thébault, E. Building the second version of the World Digital Magnetic Anomaly Map (WDMAM) // Earth Planets Space, 2016, v. 68, N 1, p.1-13.

Li C.-F., Lu Y., Wang J. A global reference model of Curie-point depths based on EMAG2 // Sci. Rep., 2017, v. 7, 45129. doi:10.1038/srep45129.

Li C.-F., Wang J. Variations in Moho and Curie depths and heat flow in Eastern and Southeastern Asia // Mar. Geophys. Res., 2016, v. 37, N 1, p. 1-20. doi:10.1007/s11001-0169265-4.

Macnab R., Verhoev J., Roest W., Arkrni-Hamed J. New database documents the magnetic character of the Arctic and North Atlantic // EOS, Trasactions. AGU, 1995, v. 76, N 45, p. 449-464.

Maus S., Dimri V.P. Scaling properties of potential fields due to scaling sources // Geophys. Res. Lett., 1994, v. 21, p. 891-894.

Maus S., Gordon D., Fairhead D.J. Curie temperature depth estimation using a selfsimilar magnetization model // Geophys. J. Int., 1997, v. 129, p. 163-168.

Maus S., Barckhausen U., Berkenbosch H. et al. EMAG2: A 2-arc-minute resolution Earth Magnetic Anomaly Grid compiled from satellite, airborne and marine magnetic measurements // Geochem. Geophys. Geosyst., 2009, v. 10, Q08005. doi:10.1029/2009GC002471.

Maus S., Yin F., Lühr H., Manoj C., Rother M., Rauberg J., Michaelis I., Stolle C., Müller R.D. Resolution of direction of oceanic magnetic lineations by the sixth-generation lithospheric magnetic field model from CHAMP satellite magnetic measurements // Geochem. Geophys. Geosyst., 2008, v. 9, Q07021. 
Mazur S., Campbell S., Green C., Bouatmani R. Extension across the Laptev Sea continental rifts constrained by gravity modeling // Tectonics, 2015, v. 34, p. 435-448. doi:10.1002/2014TC003590.

McEnroe S.A., Langenhorst F., Robinson P., Bromiley G.D., Cliff S.J.S. What is magnetic in the lower crust? // Earth Planet. Sci. Lett., 2004, v. 226(1-2), p. 175-192.

McEnroe S.A., Robinson P., Church N., Purucker M. Magnetism at depth: A view from an ancient continental subduction and collision zone // Geochem. Geophys. Geosyst., 2018, v. 19, p. 1123-1147. https://doi.org/10.1002/2017GC007344.

Meyer B., Chulliat A., Saltus R. Derivation and error analysis of the earth magnetic anomaly grid at 2 arc min resolution version 3 (EMAG2v3) // Geochem. Geophys. Geosyst., 2017, v. 18, p. 4522-4537. https://doi.org/10.1002/2017GC007280.

Nozharov P., Veljovich D. Paleomagnetic investigation of some rocks from the Carpatho-Balkanides on the territory of Bulgaria (rocks with normal and reversed magnetization) // Bulg. Geophys. J., 1983, v. 9, p. 130-138.

Okubo Y., Graf R.J., Hansen R.O., Ogawa K., Tsu H. Curie point depths of the island of Kyushu and surrounding areas, Japan // Geophysics, 1985, v. 50, p. 481-494.

Okubo Y., Matsunaga T. Curie point depth in northeast Japan and its correlation with regional thermal structure and seismicity // J. Geophys. Res., 1994, v. 99, N B11, p. 2236322371.

Pedersen H.A., Debayle E., Maupin V. and the POLENET/LAPNET Working Group Strong lateral variations of lithospheric mantle beneath cratons - example from the Baltic Shield // Earth Planet. Sci. Lett., 2013, v. 383, p. 164-172. http://dx.doi.org/10.1016/j.epsl.2013.09.024.

Petrov O., Morozov A., Shokalsky S., Kashubin S., Artemieva I.M., Sobolev N., Petrov E., Ernst R.E., Sergeev S., Smelror M. Crustal structure and tectonic model of the Arctic Region // Earth Sci. Rev., 2016, v. 154, p. 29-71. http://dx.doi.org/10.1016/j.earscirev.2015.11.013.

Pirttijärvi M. 2D Fourier domain operations, FOURPOT program. 2015. https://wiki.oulu.fi/x/0oU7AQ/.

Ravat D., Pignatelli A., Nicolosi I., Chiappini M. A study of spectral methods of estimating the depth to the bottom of magnetic sources from near-surface magnetic anomaly data // Geophys. J. Int., 2007, v. 169, p. 421-434. doi:10.1111/j.1365-246X.2007.03305.x. 
Rickers F., Fichter A., Trampert J. The Iceland-Jan Mayen plume system and its impact on mantle dynamics in the North Atlantic Region: evidence from full-waveform inversion // Earth Planet. Sci. Lett., 2013, v. 367, p. 39-51. http://dx.doi.org/10.1016/j.epsl.2013.02.022.

Salazar J. M., Vargas C.A., Leon H. Curie point depth in the SW Caribbean using the radially averaged spectra of magnetic anomalies // Tectonophysics, 2017, v. 694, p. 400-413. https://doi.org/10.1016/j.tecto.2016.11.023.

Salem A., Green C., Ravat D., Singh K.H., East P., Fairhead J.D., Morgen S., Biegert E. Depth to Curie temperature across the central Red Sea from magnetic data using the de-fractal method // Tectonophysics, 2014, v. 624-625, p. 75-86. https://doi.org/10.1016/j.tecto.2014.04.027.

Saltus R., Miller E., Gaina C., Brown P. Regional magnetic domains of the circumarctic: a framework for geodynamic interpretation // Geol. Soc. Lond. Mem., 2011, v. 35, N 1, p. 49-60.

Seredkina A. S-wave velocity structure of the upper mantle beneath the Arctic region from Rayleigh wave dispersion data // Phys. Earth Planet. Inter., 2019, v. 290. p. 76-86. https://doi.org/ doi.org/10.1016/j.pepi.2019.03.007.

Seredkina A.I., Melnikova V.I. New data on earthquake focal mechanisms in the Laptev Sea region of the Arctic-Asian seismic belt // J. Seismol., 2018, v. 22, N 5, p. 1211-1224. https://doi.org/10.1007/s10950-018-9762-9

Spector A., Grant S. Statistical models for interpreting aeromagnetic data // Geophysics, 1970, v. 35, p. 293-302.

Stacey F.D., Banerjee S.K. The physical principles of rock magnetism. Amsterdam, Netherlands, Elsevier, 1974, 195 p.

Tanaka A. Magnetic and seismic constraints on the crustal thermal structure beneath the Kamchatka Peninsula / Volcanism and tectonics of the Kamchatka Peninsula and adjacent arcs / Geophysical Monograph Series, v. 172, Washington DC, USA, AGU, 2007, p. 100-105.

Tanaka A. Global centroid distribution of magnetized layer from World Digital Magnetic Anomaly Map // Tectonics, 2017, v. 36, p. 3248-3253. https://doi.org/10.1002/2017TC004770.

Tanaka A., Ishikawa Y. Crustal thermal regime inferred from magnetic anomaly data and its relationship to seismogenic layer thickness: The Japanese islands case study // Phys. Earth Planet. Inter., 2005, v. 152. p. 257-266. doi:10.1016/j.pepi.2005.04.011.

Tanaka A., Okubo Y., Matsubayashi O. Curie point depth based on spectrum analysis of the magnetic anomaly data in East and Southeast Asia // Tectonophysics, 1999, v. 306, p. 461470. 
Trifonova P., Zhelev Zh., Petrova T., Bojadgieva K. Curie point depths of Bulgarian territory inferred from geomagnetic observations and its correlation with regional thermal structure and seismicity // Tectonophysics, 2009, v. 473, p. 362-374. doi:10.1016/j.tecto.2009.03.014.

Tsvetkov Y.P., Novikov K.V., Ivanov A.A., Brekhov O.M. Sources of the lithosphere magnetic field based on magnetic data obtained at different heights // Earth Planets Space, 2018, v. 70, p. 183. https://doi.org/10.1186/s40623-018-0955-9.

Verhoef J.R., Macnab R., Roest W., Arkani-Hamed J. Magnetic anomalies of the Arctic and North Atlantic Oceans and adjacent land areas. Open File 3125a, 1996, Geological Survey of Canada.

Wasilewski P.J., Mayhew M.A. The Moho as a magnetic boundary revisited // Geophys. Res. Lett., 1992, v. 19, N 22, p. 2259-2262.

Wasilewski P.J., Thomas H.H., Mayhew M.A. The Moho as a magnetic boundary // Geophys. Res. Lett., 1979, v. 6. p. 541-544.

Wen L., Kang G., Bai C., Gao G. Studies on the relationships of the Curie surface with heat flow and crustal structures in Yunnan Province, China, and its adjacent areas // Earth Planets Space, 2019, v. 71, p. 85. https://doi.org/10.1186/s40623-019-1063-1.

Witter J., Miller C. Curie point depth mapping in Yukon // Open File 2017-3, Whitehorse, Canada: Yukon Geological Survey, 2017, 37p. https://doi.org/10.13140/RG.2.2.28506.34242. 


\section{СВЕДЕНИЯ ОБ АВТОРАХ}

Середкина Алена Игоревна, Федеральное государственное бюджетное учреждение науки Институт земного магнетизма и распространения радиоволн им. Н.В. Пушкова Российской академии наук (ИЗМИРАН), старший научный сотрудник.

ale@crust.irk.ru

Тел. 89021776994

Адрес: 108840, г. Москва, г. Троицк, Калужское шоссе, 4

Филиппов Сергей Витальевич, Федеральное государственное бюджетное учреждение науки Институт земного магнетизма и распространения радиоволн им. Н.В. Пушкова Российской академии наук (ИЗМИРАН), заведующий лабораторией, старший научный сотрудник.

sfilip@izmiran.ru

Тел. 84958519771

Адрес: 108840, г. Москва, г. Троицк, Калужское шоссе, 4

Переписку вести с А.И. Середкиной 
Рис. 1. Область исследования с положением окон 300 х 300 км, в пределах которых проводились расчеты параметров МАС (см. далее). Рельеф приведен согласно модели ETOPO1 [Amante, Eakins, 2009].

Рис. 2. Литосферное геомагнитное поле Арктики на разных высотах: 4 км согласно модели EMAG2v3 [Meyer et al., 2017] (a), 5 км согласно модели WDMAM 2.0 [Dyment et al., 2015; Lesur et al., 2016] (б) и 350 км согласно модели MF6 [Maus et al., 2008] (в).

Рис. 3. а) - модели EMAG2v3 и WDMAM 2.0 для территорий шельфа моря Лаптевых и складчатых поясов Аляски; б), в) - соответствующие этим моделям, азимутальноусредненные Фурье-спектры мощности аномалий геомагнитного поля, по которым вычислялись параметры МАС - глубины центра масс (б) и верхней границы (в). Серые кривые на (б, в) - спектры для модели EMAG2v3, к которой добавлен случайный шум с максимальной амплитудой \pm 167 нТл (море Лаптевых) и \pm 36 нТл (складчатые пояса Аляски). Синие и красные линии на (б, в) - линейные зависимости, аппроксимирующие данные спектры методом наименьших квадратов. На врезках к (а) показана модель EMAG2v3 с добавлением соответствующего шума.

Рис. 4. Мощность земной коры в Арктике согласно [Seredkina, 2019] (а) и глобальной модели CRUST 1.0 [Laske et al., 2013] (б).

Рис. 5. Зависимости глубины нижней границы МАС (табл. 2) от различных параметров литосферы Арктики: (а) - модуля полного вектора литосферного геомагнитного поля на высоте 350 км (Та) согласно модели MF6 [Maus et al., 2008]; (б) - средней температуры в диапазоне глубин 80-150 км [Artemieva, 2006; Lebedev et al., 2017]; (в) - мощности литосферы [Seredkina, 2019]; (г) - мощности земной коры [Seredkina, 2019]. Пунктиром обозначена глубина нижней границы МАС, совпадающая с Мохо. 
Табл. 1. Средняя температура в диапазоне глубин 80-150 км.

\begin{tabular}{|c|c|c|}
\hline \multirow{2}{*}{ Регион } & \multicolumn{2}{|c|}{ T, ${ }^{\circ} \mathrm{C}$} \\
\cline { 2 - 3 } & [Artemieva, 2006] & [Lebedev et al., 2017] \\
\hline Балтийский щит & 780 & 900 \\
\hline Восточно-Европейская платформа & 860 & 850 \\
\hline Западно-Сибирская плита & 1130 & 950 \\
\hline Сибирская платформа & 860 & 950 \\
\hline Канадский щит & 850 & 600 \\
\hline северная Гренландия & 900 & 800 \\
\hline центральная Гренландия & 900 & 800 \\
\hline Верхоянский складчатый пояс & 1140 & 1100 \\
\hline Колымский складчатый пояс & 1000 & 1500 \\
\hline Чукотский складчатый пояс & 1140 & расплав \\
\hline складчатые пояса Аляски & 1140 & 1400 \\
\hline Исландия & 1270 & расплав \\
\hline
\end{tabular}


Табл. 2. Результаты расчетов параметров МАС.

\begin{tabular}{|c|c|c|c|c|c|c|c|c|c|c|c|c|c|c|}
\hline \multirow[t]{2}{*}{ № } & \multirow{2}{*}{ Регион } & \multicolumn{2}{|c|}{$\begin{array}{c}\text { Координаты } \\
\text { центральной точки }\end{array}$} & \multicolumn{5}{|c|}{ EMAG2v3 } & \multicolumn{5}{|c|}{ WDMAM 2.0} & \multirow{2}{*}{$\begin{array}{r}Z_{\mathrm{bcp}}, \\
\mathrm{KM}\end{array}$} \\
\hline & & $\varphi^{\circ}$ & $\lambda^{\circ}$ & $\begin{array}{l}Z_{\mathrm{t}}, \\
\mathrm{KM}\end{array}$ & $\begin{array}{l}Z_{0}, \\
\mathrm{KM}\end{array}$ & $\begin{array}{l}Z_{\mathrm{b}}, \\
\mathrm{KM}\end{array}$ & $\begin{array}{l}\varepsilon_{\mathrm{t}}, \\
\mathrm{KM}\end{array}$ & $\begin{array}{l}\varepsilon_{0}, \\
\mathrm{KM}\end{array}$ & $\begin{array}{l}Z_{\mathrm{t}}, \\
\mathrm{KM}\end{array}$ & $\begin{array}{l}Z_{0}, \\
\mathrm{KM}\end{array}$ & $\begin{array}{l}Z_{\mathrm{b}}, \\
\mathrm{KM}\end{array}$ & $\varepsilon_{\mathrm{t}}$ & $\varepsilon_{0}$ & \\
\hline 1 & Балтийский щит & 68 & 25 & 2.5 & 20.3 & 38.1 & 0.10 & 2.47 & 2.1 & 19.7 & 37.3 & 0.15 & 1.62 & 37.7 \\
\hline 2 & Восточно-Европейская платформа & 65 & 50 & 2.6 & 17.5 & 32.4 & 0.31 & 2.09 & 2.7 & 18.7 & 34.7 & 0.20 & 1.39 & 33.6 \\
\hline 3 & Западно-Сибирская плита & 65 & 75 & 2.6 & 19.3 & 36.0 & 0.30 & 2.33 & 3.0 & 18.4 & 33.8 & 0.24 & 2.19 & 34.9 \\
\hline 4 & Сибирская платформа & 65 & 105 & 3.2 & 17.1 & 31.0 & 0.32 & 1.67 & 3.0 & 17.9 & 32.8 & 0.08 & 1.21 & 31.9 \\
\hline 5 & Канадский щит & 67 & 255 & 3.0 & 17.4 & 31.8 & 0.12 & 1.99 & 2.8 & 17.8 & 32.8 & 0.25 & 1.24 & 32.3 \\
\hline 6 & северная Гренландия & 76 & 320 & 2.9 & 20.4 & 37.9 & 0.36 & 1.78 & 1.7 & 20.0 & 38.3 & 0.12 & 1.83 & 38.1 \\
\hline 7 & центральная Гренландия & 70 & 320 & 2.2 & 16.1 & 30.0 & 0.25 & 0.77 & 3.3 & 15.8 & 28.3 & 0.20 & 1.42 & 29.2 \\
\hline 8 & Верхоянский складчатый пояс & 65 & 132 & 2.7 & 18.6 & 34.5 & 0.16 & 1.16 & 1.9 & 17.3 & 32.7 & 0.11 & 1.41 & 33.6 \\
\hline 9 & Колымский складчатый пояс & 65 & 155 & 3.4 & 14.2 & 25.0 & 0.22 & 0.78 & 3.5 & 14.5 & 25.5 & 0.09 & 1.06 & 25.3 \\
\hline 10 & Чукотский складчатый пояс & 67 & 175 & 3.5 & 15.5 & 27.8 & 0.32 & 1.67 & 3.5 & 15.8 & 28.1 & 0.13 & 0.96 & 28.0 \\
\hline 11 & складчатые пояса Аляски & 65 & 210 & 3.6 & 16.7 & 29.8 & 0.13 & 1.82 & 2.8 & 16.8 & 30.8 & 0.12 & 1.75 & 30.3 \\
\hline 12 & Исландия & 65 & 340 & 3.3 & 14.7 & 26.1 & 0.23 & 1.42 & 2.1 & 14.0 & 25.9 & 0.13 & 1.26 & 26.0 \\
\hline 13 & Баренцево море & 75 & 40 & 1.7 & 18.5 & 35.3 & 0.29 & 0.80 & 1.5 & 19.1 & 36.7 & 0.14 & 1.88 & 36.0 \\
\hline 14 & Карское море & 78 & 78 & 2.1 & 17.3 & 32.5 & 0.19 & 1.20 & 2.7 & 16.6 & 30.5 & 0.16 & 1.03 & 31.5 \\
\hline 15 & море Лаптевых & 76 & 125 & 1.9 & 20.2 & 38.5 & 0.22 & 1.66 & 2.2 & 19.5 & 36.8 & 0.20 & 1.45 & 37.7 \\
\hline 16 & Восточно-Сибирское море & 74 & 170 & 2.0 & 17.9 & 33.8 & 0.23 & 1.38 & 2.6 & 17.3 & 32.0 & 0.21 & 1.42 & 32.9 \\
\hline 17 & Гренландско-Норвежский бассейн & 75 & 0 & 2.9 & 15.4 & 27.9 & 0.31 & 2.25 & 1.8 & 14.5 & 27.2 & 0.15 & 1.59 & 27.6 \\
\hline 18 & Евразийский бассейн & 87 & 90 & 3.5 & 16.1 & 28.7 & 0.20 & 2.40 & 3.1 & 15.8 & 28.5 & 0.10 & 2.34 & 28.6 \\
\hline 19 & котловина Макарова & 86 & 160 & 3.5 & 14.7 & 25.9 & 0.30 & 0.90 & 3.3 & 15.5 & 27.7 & 0.21 & 1.17 & 26.8 \\
\hline 20 & Канадский бассейн & 80 & 220 & 2.8 & 15.3 & 27.8 & 0.24 & 1.02 & 3.4 & 14.9 & 26.4 & 0.15 & 1.04 & 27.1 \\
\hline
\end{tabular}




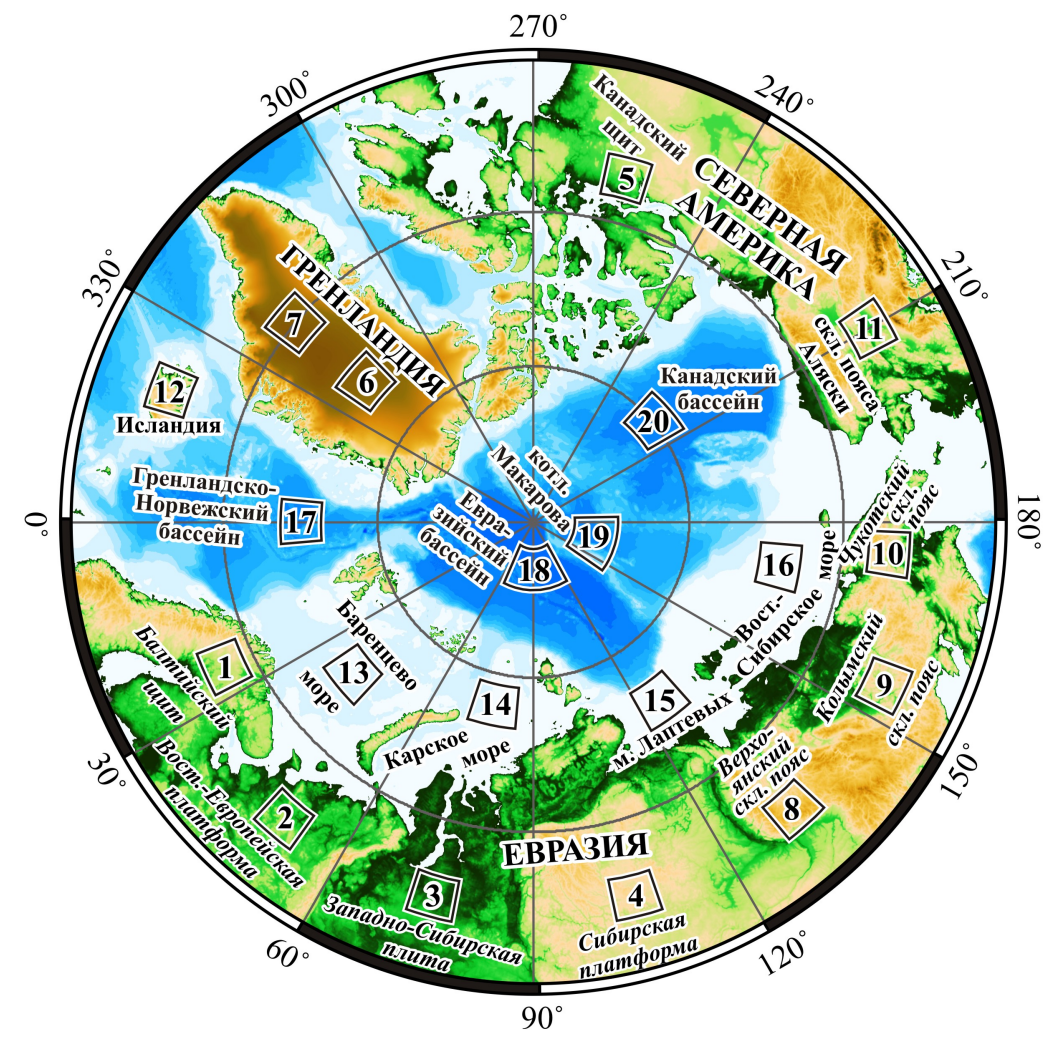



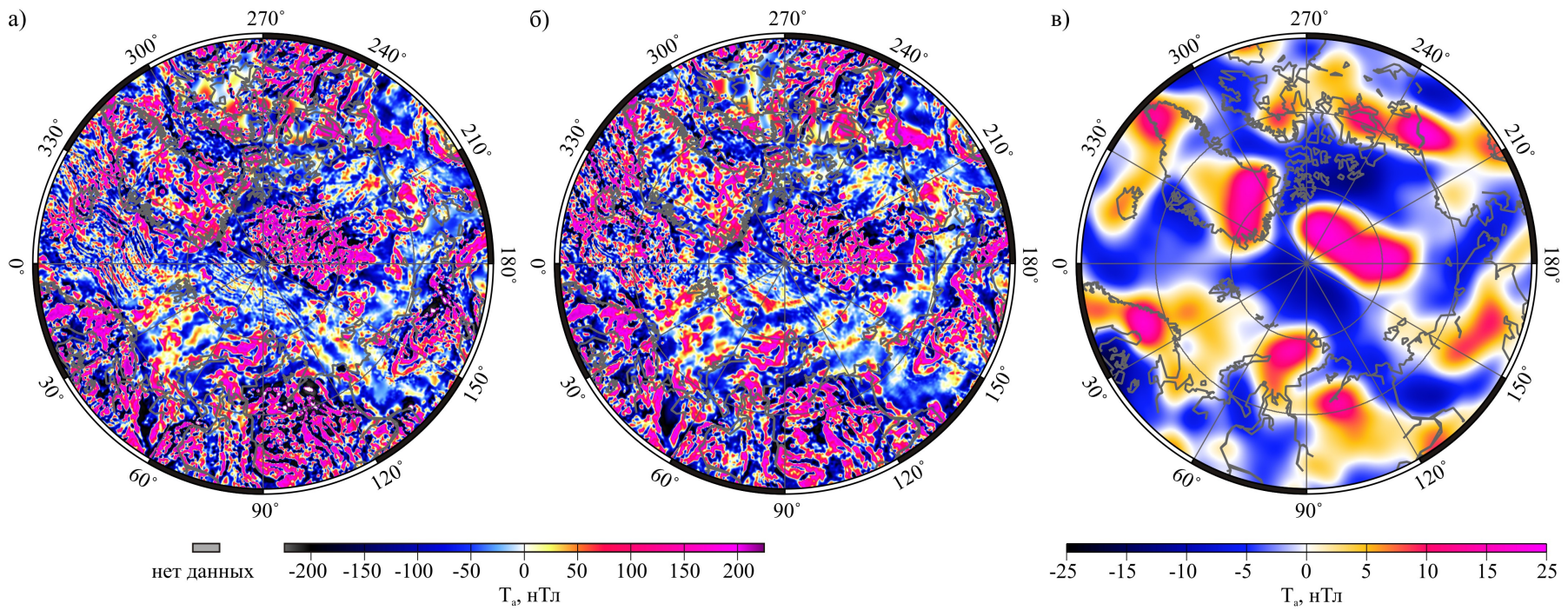

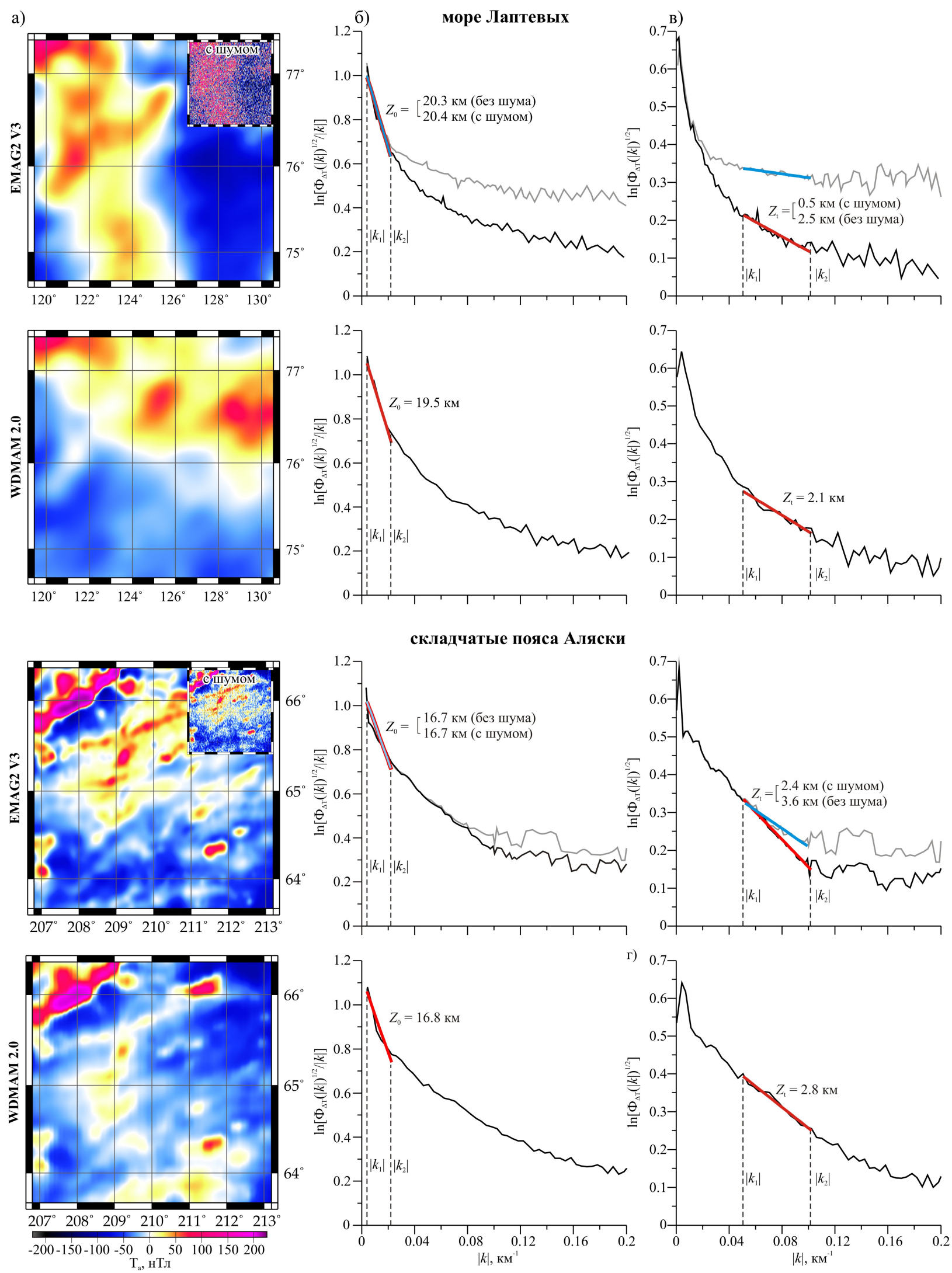
a)

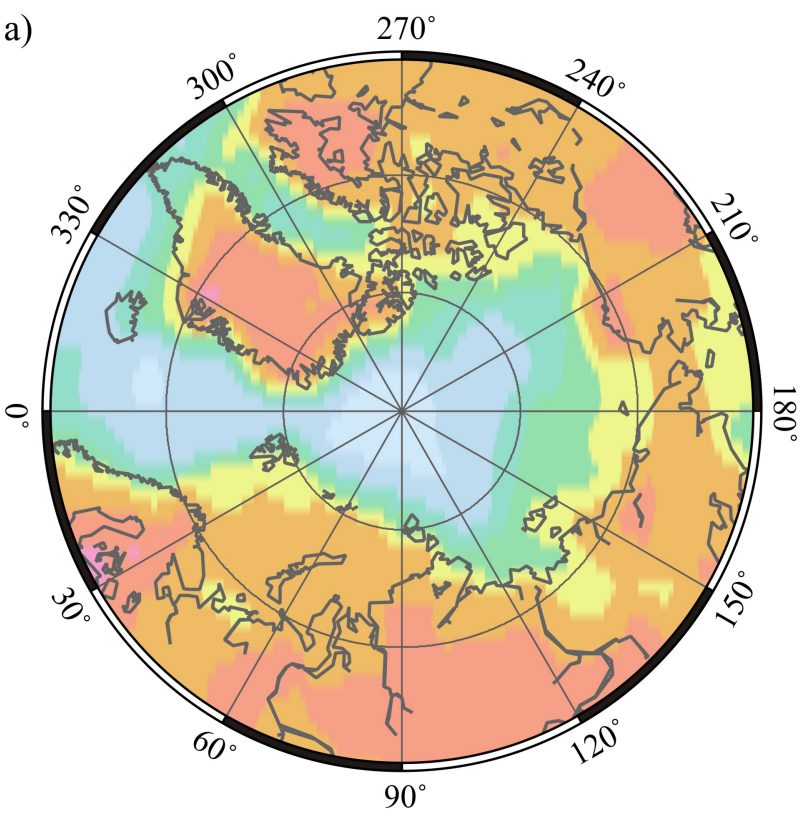

б)
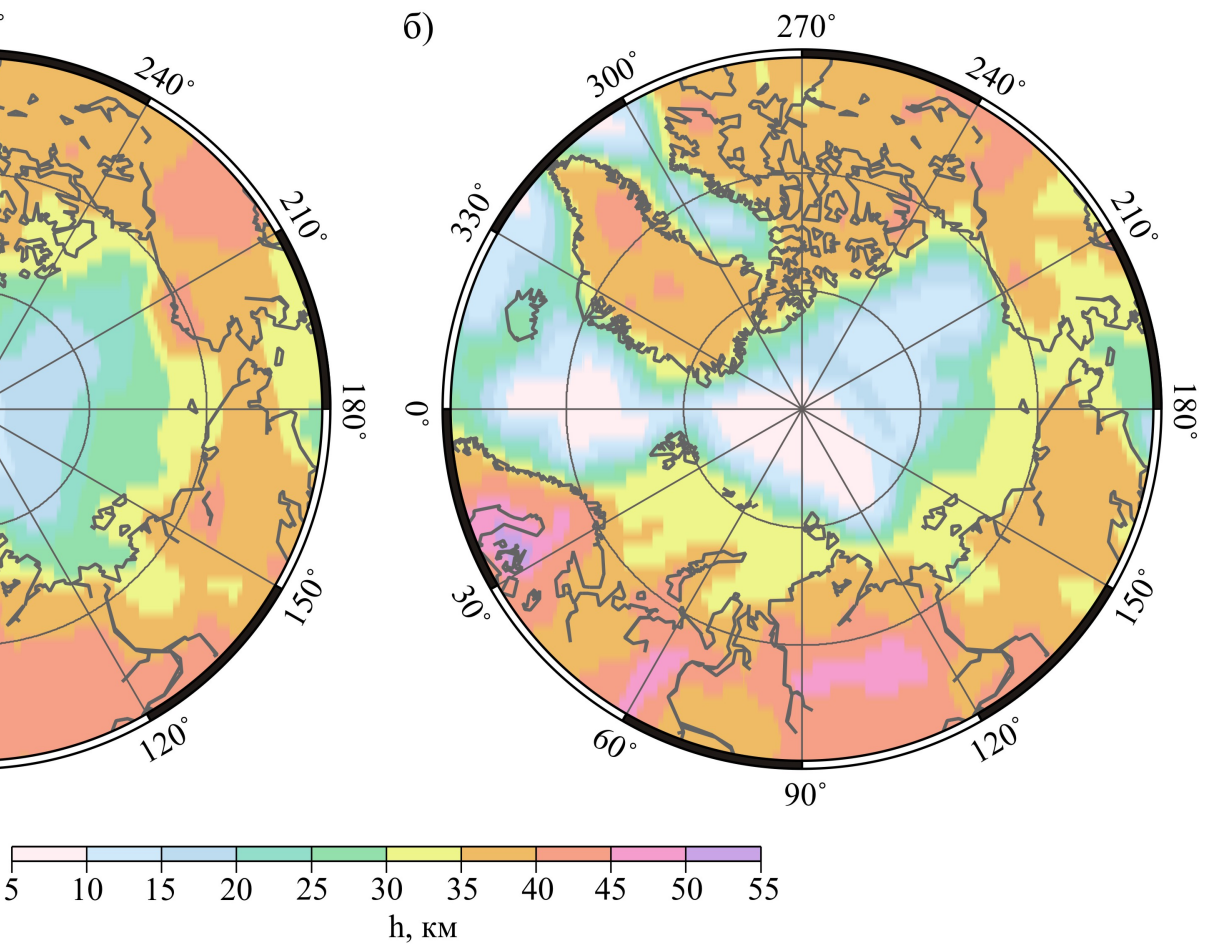
a)

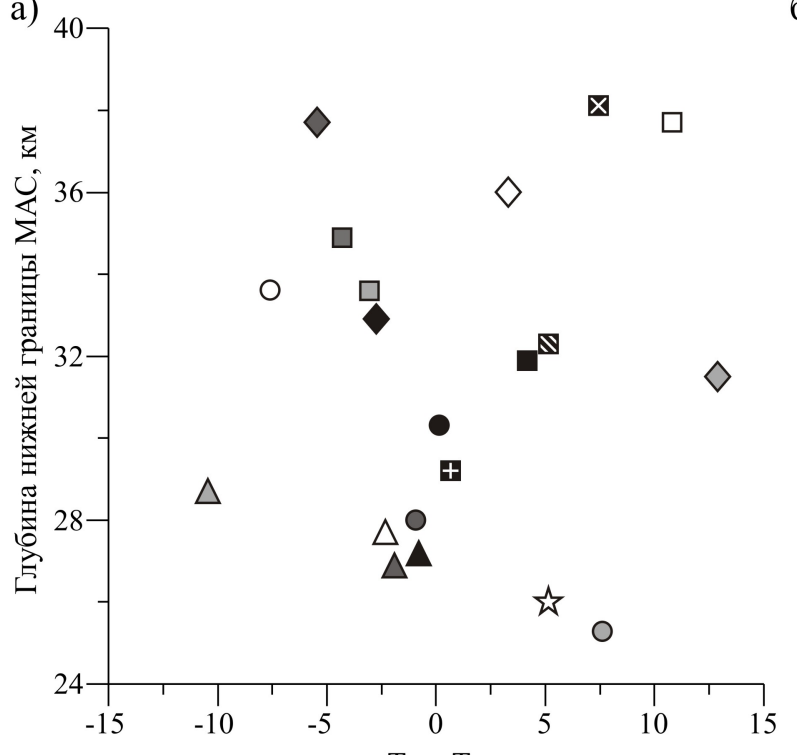

в)

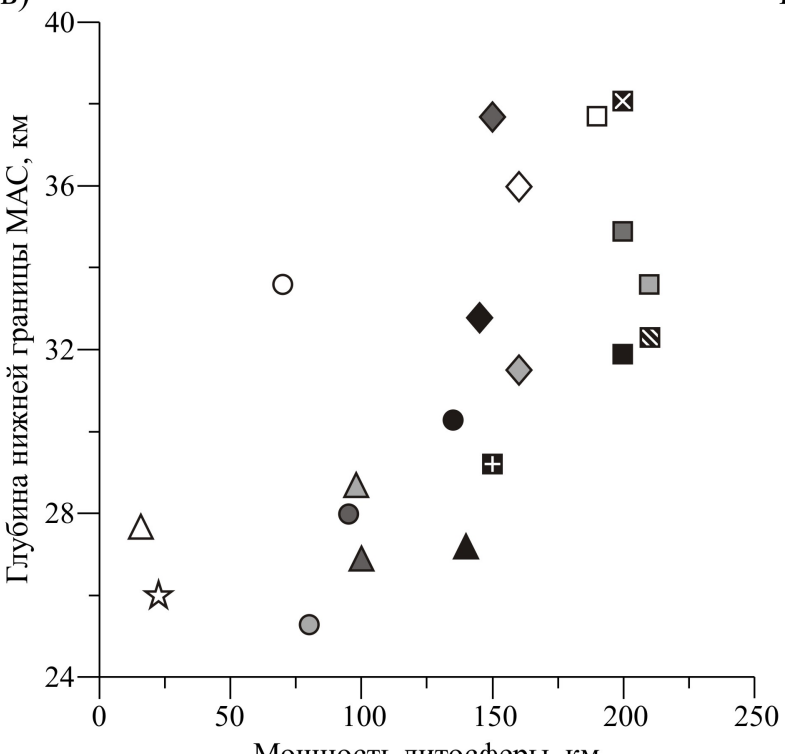

б)

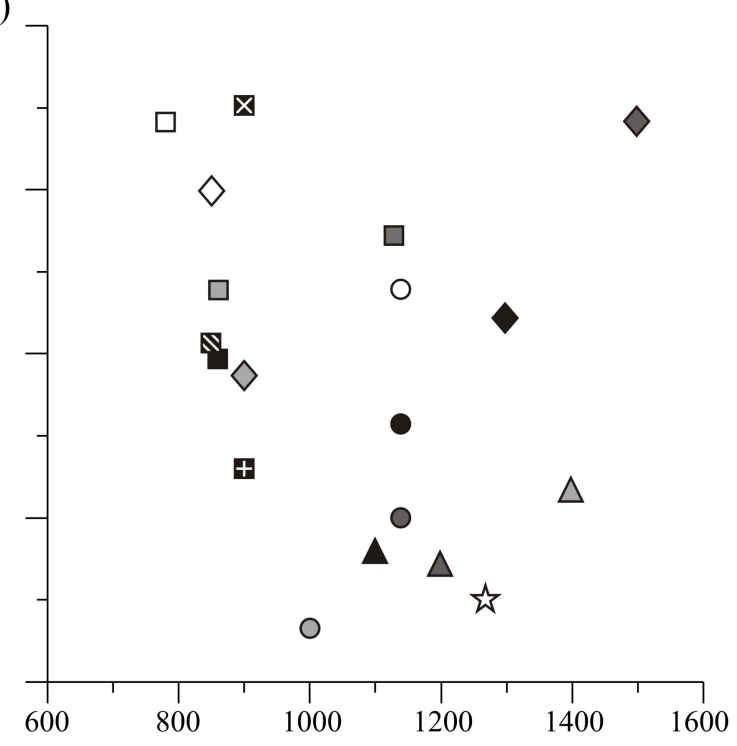

г)

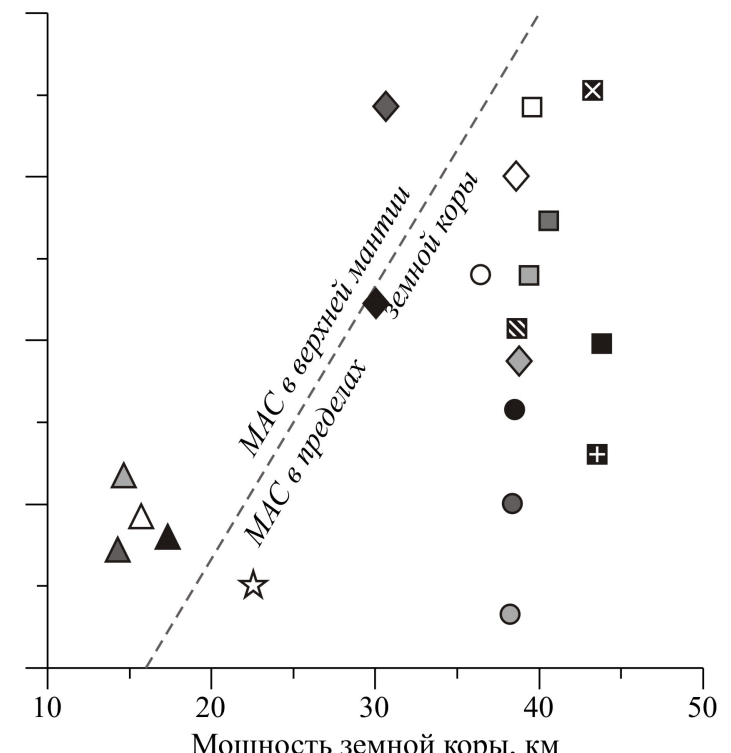

\begin{tabular}{|ll}
\hline & Балтийский щит \\
$\square$ & Восточно-Европейская платформа \\
$\square$ & Западно-Сибирская плита \\
$\mathbf{\square}$ & Сибирская платформа \\
$\mathbf{N}$ & Канадский щит \\
$\mathbf{x}$ & северная Гренландия \\
$\mathbf{+}$ & центральная Гренландия \\
\hline
\end{tabular}

○ Верхоянский складчатый пояс

○ Колымский складчатый пояс

○ Чукотский складчатый пояс

- складчатые пояса Аляски

\. Исландия

$\diamond$ Баренцево море

$\diamond$ Карское море $\diamond$ море Лаптевых

- Восточно-Сибирское море

$\triangle$ Гренландско-Норвежский бассейн

$\triangle$ Евразийский бассейн

$\triangle$ котловина Макарова

- Канадский бассейн 